\title{
Keypoint Analysis of the Pre-settlement Audit Work of the Construction project cost
}

\author{
inbao Cao ${ }^{1, \text { a }}$,Yunzhu Liu, , , Jian Tang ${ }^{1, c}$ \\ Nanchang Institute of Technology, Nanchang 330044, China \\ a1710434953@qq.com, b85429612@qq.com, ${ }^{c} 176024108 @ q q . c o m$
}

\begin{abstract}
Keywords:The analytical solution scheme of the problem of thepre settlement audit work of the construction project cost

Abstract: The pre settlement audit work of the construction project cost is a key job in the construction engineering, and is also the most basic work in building engineering. The pre settlement audit work of the construction project cost is the key to the cost control of construction engineering. Economic globalization brings new opportunities to every industry, but also proposes new requirementsto the development of every industry and increases the market competition.Facing the fierce market competition, if the construction industry wants to have a sustained and stable development, it is necessary to have a strict control of the cost of construction project.The pre settlement audit work of the construction project cost has an important impact on the cost of construction project, but at present there are many problems in the pre settlement audit work of the construction project cost in our country, which has seriously hindered the long-term development of China's construction industry. Therefore, this paper firstly gives a brief introduction to the pre settlement audit work of the construction project cost, and has a further analysis of the problems in thepresettlement audit work of the construction project cost, and finally puts forward the corresponding measures, hoping to help to improve the current situation of the pre settlement audit work of the construction project cost in our country and promote the the further development of China's construction industry.
\end{abstract}

\section{Introduction}

The pre settlement audit work of the construction project cost has very important effect, and at present, the pre settlement audit work of the construction project costhas been identified as an important means and the necessary procedure of construction project $\operatorname{cost}^{[1]}$. Therefore, the pre settlement audit work of the construction project cost has received more and more attention. But the study shows that, although China's pre settlement audit work of the construction project costhas made some progressin recent years, but at present China's pre settlement audit work of the construction project cost still have many problems, which has serious influence on the cost quality of the construction engineering in China, and further hinders the long-term development of the construction industry in our country ${ }^{[2]}$. This paper mainly analyzes content and key points of the work of thepre settlement audit work of the construction project cost, and further analyzes the present problem in thepre settlement audit work of the construction project cost and puts forward the corresponding solutions.

The pre settlement audit work of the construction project cost is mainly to conduct a strict control and audit of human resources cost, the raw material purchase cost and construction periodbefore the construction project. The pre settlement audit work of the construction project cost can not only reduce the construction cost of engineering construction effectively, but also can further ensure the construction quality of construction the project. In addition, the pre settlement audit work of the construction project cost is not only an important foundation of construction drawing review project funding, but also the important documents of signing construction operation contract and the construction material purchase contract, which can show the importance of the pre settlement audit work of the construction project cost.Only to ensure the pre settlement audit work of the construction project cost, can further guarantee the quality of the construction project, and the 
economic benefits of the construction unit, and further promote the sustained and stable development of China's construction industry ${ }^{[3]}$.

The workload measurements have both positive and negative errors. The positive error mainly refers to that the excavation height of the design chart is bigger than the actual excavation height after the earthwork excavation. For example: whether the occupied areas of the indoor railway, trench, equipment foundation and the prominent ground buildings are deducted at design time. Negative error the workload measurement mainly refers to the calculated workload in the case of the workload omission through the theoretical size to have the calculation of the building size ${ }^{[4]}$. Therefore, the pre settlement audit work of the construction project cost should first be familiar with the design drawings for the construction, and have a strict workload calculation according to the fixed design amount, should focus on the audit on the project which is easy for some errors to avoid repeated calculation errors in workload. Secondly, the project with the use scope should have strict audit. Finally, the part with the discrepancy between the drawings and the actual construction should be reviewed. At the same time, some construction parts do not construct in accordance with the drawings because of the interests, which will affect the quality of the construction, so it requires the audit staff inspect the construction site, obtain accurate data and ensurethe workload accuracy ${ }^{[5]}$.

The engineering cost is authoritative, scientific and legal, so whoever uses the content, form and quantity standard of engineering cost must have strict implementation of the relevant standards and rules, and can not arbitrarily change. At the same time, in the pre settlement audit work of the construction project cost, we should also pay attention to the following aspects: 1 . Whether the project has repeated use, for example: the iron of the prefabricated components, the waterproof layer of asphalt membrane and the drainage equipment which belongs to construction engineering stone category and so on. If the comprehensive quota method is used for the budget, it is very easy to appear the phenomenon of repeated use of engineering project. 2, Have the audit of direct application of the fixed unit price. In the audit of direct apply quota unit price, special attention should be paid to whether the content and name of the project are in accordance with the related requirements of the design drawings, for example: the strength of the project, the form of the cross section and so on. 3, Have the audit of the conversion of the fixed unit price. When having the audit on the conversion of the fixed price, the material, labor and so on of the conversion projects should be reviewed, at the same time we should also further examine the conversion method, whether the used conversion coefficient is correct, because if there are errors in these factors, it will seriously affect the correctness of the, which will cause some impact on the entire construction project cost. Regional differences will cause a certain impact on the project cost, so in the calculation of the engineering cost, the local standards of the the construction engineering should be strictly treated as the basis. In the engineering cost audit, first we should have the analysis whether engineering cost quota is capable of having a clear distinction with the engineering installation, decoration, repair and properties construction. Secondly, we should also have a strict audit of engineering category, the cost rate of the project cost calculation, the construction contract and bidding documents of the related departments .

\section{The problems}

Using inferior materials and turning out substandard goods is the most common and the most prominent problem in the building construction process, which is mainly presented in the two aspects of inappropriateprice controland the intention to shorten the project time. Thepreset pre settlement audit work of the construction project costwill usually clarify the basic price of building materialsin the material quota, but the actual price of building materials will make the corresponding adjustment in the whole material of similar products in the market, so there will be a significant difference between the market price and the material quota, which is the most obvious 
problem existing in the pre settlement audit work of the construction project cost. At the same time, the cost management department has some obstacles in the communication with the construction departmentbecause of the lack of comprehensivecost engineering management knowledge, so in the review and development process of the material quota, which will cause the change of the materialprice can not be timely reported to the materials department, forming the cost increase and finally leading to the phenomenon of the emergence of large holes in the pre settlement audit work of the construction project cost.

Deliberately raising the project cost is a common problem existing in the construction engineering. The cause of the problem is mainly due to the problems existing in the coordination between the construction part and cost management department, and affect the construction engineering progress, which will lead to that the construction part will put the requirement of the time cost, but as the coordination between the construction side and cost management departments has somecommunication problems, so this part of the cost is not included in the pre settlement audit work of the construction project cost, and then the pre settlement audit work of the construction project cost has the data distortionin the case of audit.

The bargaining model is mainly used for the earthwork the scattered projects involved in the construction engineering, but does not take a fixed way. The the false phenomenon will appear in the pre settlement audit work of the construction project cost. To carry out the construction in this form can not ensure the effectiveness of current price, which will make the pre settlement audit work fall into the misunderstanding .

The engineering quantity increase will lead to the increase of the construction cost, so the audit of the calculated construction workload has been by should be carried out from the calculation rules of the building, professional equipment material table, quota and the engineering ${ }^{[6]}$. When auditing, it should be focused on whether the calculation of workload examination has the phenomenon of leaking, wrong and roll back calculation. At the same time, the audit should focus on the overall and careful inspection and check of the construction, while other sub projects can use the review with the general method. Note that in the workload audit, we should pay special attention to the workload calculation method and the source of the size data.

The pre settlement audit work of the construction project cost needs to spend a lot of time and energy, so it can be said that the pre settlement audit work of the construction project cost is a systematic and complex project, and every detail of the audit work is closely linked to the final results of the audit ${ }^{[7]}$. Therefore, in order to effectively improve the quality of the pre settlement audit work of the construction project cost, we should focus on the audit of the project in the audit to ensure that the large project auditis correct, and then investigate the small projects of the construction engineering one by one. Clutch large projects and pay attention to small details, which is an important means of improving the pre settlement audit work of the construction project cost. Construction drawings of the building engineering is an important basis for cost and bidding for construction projects.In order to ensure the effectiveness of the pre settlement audit work of the construction project cost, in the audit work, we should increase the construction organization design audit. In general, different construction organization design schemes haveobviously different construction costs. In the design, the design constitute will design according to the routine project construction, but in the construction practice, the construction side will select the optimal design scheme and construction equipment according to the actual situation of the construction project, so as to realize the largest economic benefits of the construction.

The quality of the pre settlement audit work of the construction project cost has close contact with the accuracy of the construction project, so we should ensure the quality ofthe pre settlement audit work of the construction project cost.First,we should make sure that there is no error calculation of engineering quantity ${ }^{[8]}$. The preparation of final accounts of construction unit will often have many count or recalculation workload phenomenonin the hidden cross sections of the construction, such as: there existsthe part where the main beam and secondary beamtransfer in construction 
engineering, and the phenomenon that calculating the secondary beam into the side of the main beam. Besides, the pre settlement audit staffof the engineering cost often base it on the beam structure of the construction engineering in the calculation of the workload. The audit staff do not deduct the joint part with the beam column, which will lead to an increase in the workload of construction project, and then improve the project cost of the entire construction project. Therefore in the process of the pre settlement audit work of the construction project cost, the audit staff should first clarify the calculation rulesof the workload, calculate strictly according to the workload calculationrules so as to ensure the authenticity of thepre settlement audit work of the construction project cost.

\section{Conclusions:}

The pre settlement audit work of the construction project cost has a significant impact on the building engineering cost, the economic benefits of the construction part and the quality of the construction quality, so it is necessary to strengthen the analysis of the problems in the pre settlement audit work of the construction project cost and further put forward the corresponding solutions

\section{References:}

[1]Liu Wanfeng.Do a good job of thepre settlement audit work, reasonably determinethe project cost [J]Gansu science and technology, 2006,22 (3): 167-168,116.

[2]Zhang Fulong. The research on the pre settlement audit work of the construction project cost[J]. Charming China, 2009, (33): 109-110.

[3]Wang Qing, The analysis of thepre settlement audit work of the construction project cost[J]. Science and technology innovation and application, 2014, (11): 198-198.

[4]Chen Xiangdan. Talk on how to do well in thepre settlement audit work of the construction project cost [J]. City construction theory research (Electronic Edition), 2013, (12).

[5]Nig Wufei. The key point of the thepre settlement audit work of the construction project cost [J]. Real estate development, 2014, (8): 214-214.

[6]Tao Yaofei. The investigation ofthepre settlement audit work of the construction project cost [J]. Urban construction theory research, 2014, (9).

[7]Lin Changzheng. The analysis of thepre settlement audit work of the construction project cost2014[J]. Low-carbon world, (12): 191-192.

[8]Qiu Yanhai. The analysis of the key points of thepre settlement audit work of the construction project cost [J]. Chinese and foreign entrepreneurs, 2014, (8): 93-93,95.

[9]Tang Rengui. The key points of the thepre settlement audit work of the construction project cost [J]. Urban construction theory research, 2014, (14). 